\title{
Hacia las realidades morales
}

\author{
Mark Platts
}

nte todo quisiera expresar mi profundo agradecimiento a
Olbeth Hansberg, Guillermo Hurtado y Margarita Valdés*, no
tanto por las cosas bellas que dicen sobre Moral realities
-aun cuando sean bienvenidas - sino más bien por el cuidado con el que han leído este libro tan difícil. No fue mi intención producir algo tan tortuosamente complejo; cuando me di cuenta de la dificultad de la penúltima versión -especialmente cuando John McDowell me comentó que le había costado mucho trabajo comprenderla- dediqué unos meses a la tarea de simplificar la estructura del libro. (En este proceso el volumen del texto se redujo en un cincuenta por ciento). El hecho de que el texto publicado siga siendo bastante difícil para el lector seguramente se debe en gran parte a deficiencias mías; pero sospecho que también se debe en parte a la naturaleza misma del tema, la filosofia moral. Entre otras complicaciones, hay múltiples concepciones sobre la naturaleza de este tema: ideas divergentes sobre el propósito del estudio de la filosofía moral, sobre la metodología adecuada para su estudio, e incluso sobre la mera posibilidad de un estudio filosófico de la moralidad. Moral realities es un intento de acercarme a una concepción de la filosofía moral: una concepción humeana en cuanto a la metodología, una concepción cognoscitiva en cuanto a los resultados, y una concepción ligeramente escéptica en cuanto a las consecuencias prácticas. Si el mundo me da el tiempo y la paz necesaria, intentaré producir otro texto menos exigente para el lector; pero mientras, repito, estoy profundamente agradecido para con estos tres colegas y amigos por la paciencia y seriedad con las que han estudiado este primer intento mío. Una de las cosas que hacen más falta

- El texto de Margarita Valdés ya fué publicado en Crítica, vol xxiv, diciembre de 1992, núm. 72 (N.E.) 
en nuestro medio filosótico es la discusión de los trabajos de nuestros colegas de una manera - como bien dice Guillermo- crítica en buena ley: discusión cuya finalidad no es formar "discipulos" ni "desprestigiar" a "rivales". Es decir: el propósito de la discusión es —o debería de serla formación de una tradición de debate filosófico: un debate motivado por la búsqueda compartida de la verdad filosófica, no por ambiciones extrafilosóficas.

Las observaciones de Margarita, Olbeth y Guillermo merecen una respuesta mucho más detallada que la que puedo ofrecerles aquí. Pero, en términos generales, diría que sus observaciones han puesto de manifiesto la necesidad de que, en el futuro, yo aclare mucho más tres temas centrales de Moral realities. En primer lugar, la noción de causalidad razonable. Como queda claro en la exposición tan inteligente de Margarita, esta noción juega un papel central en las teorías positivas de Moral realities -especialmente en el intento de reconciliar una teoria cognoscitivade algunas partes de nuestro pensamiento moral con el reconocimiento del carácter práctico de tal pensamiento. Por lo tanto la insistencia en que se diga algo más sobre esta noción es - ¿cómo no?- razonable. Sospecho que, en último término, esta noción es tan coherente como la noción distinta de causalidad racional; pero para apoyar - irazonablemente!esta sospecha mía sería necesario exponer y defender las ideas del Wittgenstein de Investigaciones filosóficas sobre la racionalidad en general y sobre las reglas lógicas en particular.

En segundo lugar está el asunto de la aplicación práctica de la taxonomía del deseo presentado en Moral realities. Tanto Olbeth como Margarita, ofrecen algunos casos difíciles de clasificar en los términos de esa taxonomía: solamente la presentación de criterios de aplicación de la taxonomía abstracta podría resolver sus dudas. Aquí sólo enfatizaré tres puntos pertinentes para el desarrollo de este tema: (i) nuestras atribuciones cotidianas de deseos casi nunca sirven para fijar la ubicación de dichos deseos dentro de la taxonomía; (ii) muchas de nuestras atribuciones cotidianas de deseos son atribuciones de deseos híbridos en relación con la taxonomía; y (iii) no se trata de la búsqueda de definiciones "operacionalistas" de las categorias abstractas de deseo distinguidas dentro de la taxonomía ofrecida.

En tercer lugar, están las cuestiones de epistemología moral y de ontologia moral involucradas en las teorías positivas de Moral realities. Guillermo insiste, con toda razón, sobre la necesidad de decir mucho más sobre estas cuestiones. En relación con la cuestión epistemológi$\mathrm{ca}$, creo que el desarrollo requerido podría provenir principalmente de la defensa de las ideas de Wittgenstein, Austin, McDowell y Paul 
Snowdon sobre la percepción en general. (No me preocuparía si tal defensa no nos ofrece un "criterio" de la verdad de nuestras creencias morales). Sobre la cuestión ontológica, solamente quisiera enfatizar aquí dos puntos: primero, el hecho de que esta cuestión requiere, en primer lugar, una contestación interna, una contestación desde el punto de vista de los agentes morales; y segundo, el hecho de que la metodología humeana de Moral realities no descuida inevitablemente esta cuestión metafísica. (Que su ontología resulte discutible es harina de otro costal). Por ejemplo: en el tercer capítulo de Moral realities intento mostrar que es una parte de la teoría interna de nuestro pensamiento evaluativo, que en algunos casos la cuestión acerca de valores no se reduce a la cuestión acerca de nuestras valoraciones. Es verdad, como dice Guillermo, que esto no implica que en estos casos nuestro pensamiento evaluativo sea defendible. Pero antes de aceptar la invitación de Guillermo a abandonar el enfoque de Moral realities sobre esta cuestión, tendría yo que tener una contestación a una nueva pregunta: si vamos a intentar el tipo de teoría metafísica de la moralidad que Guillermo parece favorecer, ¿desde qué punto de vista - desde el punto de vista de quiénes - hemos de entender la teoría resultante? 